\title{
Tp-e Interval, Tp-e/QT and Tp-e/QTc Ratios in Female Patients with Small Heart Syndrome
}

\section{Küçük Kalp Sendromlu Kadın Hastalarda Tp-e Aralığı, Tp-e/QT ve Tp-e/ QTc Oranları}

\section{(D) Ersin İbişoğlu1, (D) Bedrettin Boyraz²}

1University of Health Sciences Turkey, Başakşehir Çam and Sakura City Hospital, Clinic of Cardiology, İstanbul, Turkey

${ }^{2}$ Doruk Hospital, Clinic of Cardiology, Bursa, Turkey

\section{Abstract}

Objective: The relevance of Tp-e, QT dispersion and the ratios between these two as predictive variables of ventricular arrhythmias, particularly ventricular prematurity depolarization and sudden cardiac death, were assessed in this study of patients who were identified with small heart syndrome.

Method: The study included 94 female patients, as 47 small-heart and 47 normal-heart patients, by calculating their cardiothoracic ratios. We measured QT max QT min' QRS, JT and Tp-e intervals, Tp-e/QT max $^{\prime} T p-e / Q T c_{\text {max }}$ Tp-e/JT and Tp-e/JTc rates and estimated $\mathrm{QTC}_{\text {max' }^{\prime}}$ QTC min' $_{\text {max }}$ CQTd and JTC intervals.

Results: cQTd, Tp-e, Tp-e/QTc $c_{\max ^{\prime}}$ and Tp-e/JTc values were significantly higher in the small heart patient group. QTc $c_{\min }$ and QTcmin values were significantly lower.

Conclusion: Tp-e and QT dispersion values are important markers in patients with small heart syndrome in terms of predicting ventricular repolarization and a possible ventricular arrhythmia.

Keywords: Electrocardiogram, small heart syndrome, ventricular repolarization

\section{Öz}

Amaç: Tp-e, QT dispersiyonu ve bu ikisi arasındaki oranlar ventriküler aritmilerin, özellikle ventriküler prematürite depolarizasyonunun ve ani kardiyak ölümün öngörücü değişkenleri olarak, bu çalışmada küçük kalp sendromu ile tanımlanan hastalarda değerlendirildi.

Yöntem: Kardiyotorasik oranları hesaplanarak 47'si küçük kalpli, 47'si normal kalpli 94 kadın hasta çalışmaya alındı. QT ${ }_{\text {maks' }}$ QT ${ }_{\text {min' }}$ QRS, JT ve Tp-e intervalleri, Tp-e/QT maks' Tp-e/QTC $c_{\text {maks' }}$ Tp-e/JT ve Tp-e/JTc oranları ölçüldü ve QTC maks QTC min' $_{\text {m }}$ cQTd ve JTc intervalleri hesaplandı.

Bulgular: Küçük kalp hasta grubunda cQTd, Tp-e, Tp-e/QTc $c_{\text {maks }}$ ve Tp-e/ JTc değerleri anlamlı olarak daha yüksekti ve QTc $c_{\text {min }}$ değerleri anlamlı olarak daha düşüktü.

Sonuç: Küçük kalp sendromlu hastalarda Tp-e ve QT dispersiyon değerleri ventriküler repolarizasyonu ve olası bir ventriküler aritmiyi öngörme açısından önemli belirteçlerdir.

Anahtar Kelimeler: Elektrokardiyografi, küçük kalp sendromu, ventriküler repolarizasyon

\section{Introduction}

Small heart syndrome, also known as neurocirculatory asthenia, is related to a small heart shadow on chest X-rays. Fatigue or exhaustion, tachycardia, pain in the abdomen, difficulty in breathing, anxiousness, shaking, sweating, and loss of consciousness are the most common conditions which are also the most detectable symptoms of cardiac arrhythmia patients $(1,2)$.

As clinical manifestations of cardiac arrhythmias like palpitations and chest pain, fatigue may also occur in our clinical routine. While arrhythmias could be reported with 24-hour electrocardiography (ECG) reading during rhythm

Address for Correspondence: Ersin Ibişoğlu, University of Health Sciences Turkey, Başakşehir Çam and Sakura City Hospital, Clinic of Cardiology, İstanbul, Turkey

E-mail: e_ibisoglu@hotmail.com ORCID: orcid.org/0000-0002-1231-0933 Received: 14.09.2021 Accepted: 10.12.2021

Cite this article as: Ibişoğlu E, Boyraz B. Tp-e Interval, Tp-e/QT and Tp-e/QTc Ratios in Female Patients with Small Heart Syndrome. Bagcilar Med Bull 2022;7(1):1-5

() Copyright 2022 by the Health Sciences University Turkey, Bagcilar Training and Research Hospital Bagcilar Medical Bulletin published by Galenos Publishing House. 
follow-up, these arrhythmias can also be difficult to identify. Therefore, ECG results may also be helpful $(3,4)$.

The repolarization process offers useful knowledge as an indicator of arrhythmia in cardiac electrophysiology relating to the chance of having an arrhythmia. As it involves the depolarization step, the QT distance is important, so the JT distance belongs to the repolarization step. Recently, in terms of sensitivity of ventricular arrhythmias and the chance of sudden cardiac death, Tp-e values, one of the determinant criteria for ventricular arrhythmias, and their association with QT and JT distances are useful measurements $(5,6)$.

The relevance of Tp-e, QT dispersion and the ratios between these two as predictive variables of ventricular arrhythmias, particularly ventricular prematurity depolarization and sudden cardiac death, were assessed in this study of patients who were identified with small heart syndrome.

\section{Materials and Methods}

The study complies with the Declaration of Helsinki. University of Health Sciences Turkey, Gazi Yaşargil Training and Research Hospital approved the study protocol on $15 / 01 / 2021$ with the number of 625 and informed consent was obtained from participants participating in the study in this article.

\section{Study Design and Population}

Ninety-four female patients, including 47 small-heart and 47 normal-heart patients, who registered between March 2018 and February 2020, were included in the study for evaluating their chest X-ray cardiothoracic ratios (CTR) (Figure 1), after obtaining the ethical committee approval. The patients were selected from those who presented to the cardiology outpatient clinic with the complaint of chest pain. None of patients have a history of coronary artery disease or another cardiac disease. Exercise test was applied to all patients and no pathology was found in the effort test. Patients and hospital registrations provided the required demographic and clinical features. Patients with metabolic or electrolyte abnormalities, systemic heart failure, acute or chronic infections, or those taking drugs that might affect the P wave, PR segment, QT and QTc intervals were not involved in the study. Complete blood count and biochemical assessments on all patients were previously carried out and the outcomes of each patient were reported.

\section{Chest Roentgenograms}

In the posteroanterior projection on the chest roentgenogram, the calculated CTR was described as small heart of $\leq 42 \%$ (7-9). Throughout the right-to-left projection of the lateral view on the chest X-ray, the existence or lack of narrow chest indications, involving the posterioranterior chest and straight back, was evaluated. Once the anteroposterior diameter was measured laterally less than $40 \%$ of the transversal diameter at the level of the diaphragm of the thoracic cavity, a narrow chest was identified.

\section{ECG Analysis}

After resting for 10 minutes, twelve leading ECGs were collected with a magnitude of $10 \mathrm{~mm} / \mathrm{mV}$ and a frequency of $25 \mathrm{~mm} / \mathrm{s}$ with typical lead positions in the standard position with a commercially available instrument. The ECG duration is $10 \mathrm{~s}$, so there were 4 to 6 beats per lead, based on the heart rate. ECG measurements were taken manually by using a magnifying glass (TorQ $150 \mathrm{~mm}$ Optical Caliper LCD) by two random cardiologists who had no patient data. By measuring the Pearson's correlation coefficient $(\mathrm{r}=0.93)$, interobserver agreement for PWPT was assessed. The QT interval of the surface ECG was calculated as the period between the starting of the QRS and the termination of the T wave. The Hodges formula was used to calculate the QTc intervals.

\section{QT Indices}

From the beginning of the QRS complex to the end of the $\mathrm{T}$ wave, which was described as its returning to the TP baseline, QT intervals were collected. The QT interval to the lowest point of the curve between the $\mathrm{T}$ and $\mathrm{U}$ waves

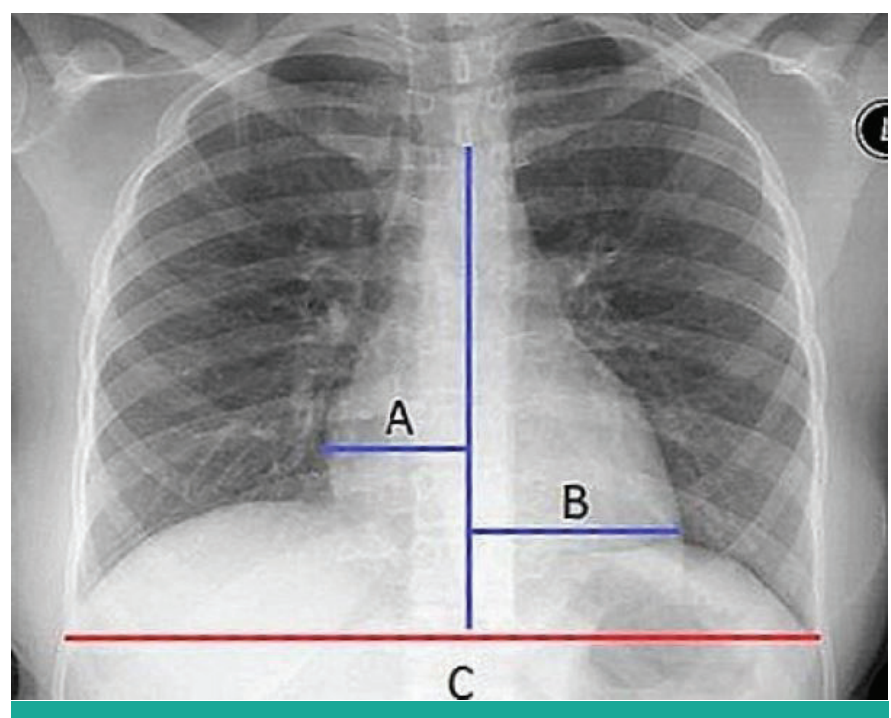

Figure 1. Measurement of cardiothoracic ratio 
was calculated when $\mathrm{U}$ waves were present. To determine the heart rate and compensate for the QT interval (QTc), the R-R interval was calculated and used with the Hodge's equation $(10,11)$. QT dispersion (QTd) was defined as the difference in separate leads between the longest and shortest QT intervals. From the T wave peak to the end of the $\mathrm{T}$ wave, the Tp-e interval was described. Tp-e interval calculations were conducted from precordial points. The Hodge's formula [QTc $=\mathrm{QT}+0.00175 \times(\mathrm{HR}-60)]$ was used to measure the rate of QTc and the corrected QT dispersion (cQTd). JT intervals were calculated from the endpoint of the QRS complex (J point) through the ending of the T wave (JTend interval). In order to calculate JTc, the Hodge's formula [JTc $=J \mathrm{~T}+0.00175 \times(\mathrm{HR}-60)]$ was used. The ratios of Tp-e/QT, Tp-e/QTc, Tp-e/JT, and Tp-e/JTc were also measured. No patient had an observable lead of less than nine. For assessments, the intra- and interobserver variations were $<5 \%$.

\section{Statistical Analysis}

The analysis was carried out using the SPSS 23.0 Statistical Package Software for Windows (SPSS Inc., Chicago, Illinois, USA). Quantitative variables were presented as mean \pm standard deviation, and qualitative variables were expressed as numbers and percentages. Variations within independent variables were evaluated by the Student's t-test for normally distributed numerical variables and the Mann-Whitney U test for non-normal distributed variables and the chi-square analysis for qualitative variables. The Kolmogorov-Smirnov test was used to determine the normality of the data. The Levene's test was employed to assess the variance homogeneity. A p-value $<0.05$ was regarded as statistically significant.

\section{Results}

There was no significant difference between the patients in the study and the control group in terms of age, weight, height, platelet, hemoglobin, creatinine, urea, alanine aminotransferase, troponin, or aspartate aminotransferase. The body mass index in the small heart group was detected as low (Table 1). In the small heart patient group, significantly higher values were recorded for cQTd $(24.246 \pm 9.046 \mathrm{~ms}$ vs. $35.495 \pm 14.358 \mathrm{~ms}, \mathrm{p}<0.001)$, Tp-e (67.32 $\pm 11.661 \mathrm{~ms}$ vs. $72.67 \pm 11.028 \mathrm{~ms}, \mathrm{p}=0.04)$, Tp-e/ $\mathrm{QTc}_{\max }(0.166 \pm 0.028$ vs. $0.181 \pm 0.027, \mathrm{p}=0.012), \mathrm{Tp}-\mathrm{e} / \mathrm{JTc}$ $(0.214 \pm 0.038$ vs. $0.232 \pm 0.034, \mathrm{p}=0.022)$. Also, the values of the small heart group for $\mathrm{QTc}_{\min }(379.34 \pm 20.064 \mathrm{~ms}$ vs. $364.71 \pm 23.149 \mathrm{~ms}, \mathrm{p}=0.004$ ) were significantly lower. No significant difference was found in the heart rate
( $87.81 \pm 15.532 \mathrm{bpm}$ vs. $83.81 \pm 14.372 \mathrm{bpm}, \mathrm{p}=0.223$ ), QRS (83.23 $\pm 6.948 \mathrm{~ms}$ vs. $81.91 \pm 10.052 \mathrm{~ms}, \mathrm{p}=0.206), \mathrm{QT}_{\max }$ (354.93 $\pm 26.796 \mathrm{~ms}$ vs. $358.54 \pm 28.434 \mathrm{~ms}, \mathrm{p}=0.528$ ), $\mathrm{QT}_{\min }$ (330.68 $\pm 26.611 \mathrm{~ms}$ vs. $323.04 \pm 30.829 \mathrm{~ms}, \mathrm{p}=0.202)$, JT $(265.7 \pm 25.16 \mathrm{~ms}$ vs. $271.88 \pm 23.104 \mathrm{~ms}, \mathrm{p}=0.218)$, QTc $\mathrm{max}_{\max }$ $(403.59 \pm 18.208 \mathrm{~ms}$ vs. $400.20 \pm 18.336 \mathrm{~ms}, \mathrm{p}=0.371)$, JTc (314.37 $\pm 21.325 \mathrm{~ms}$ vs. $313.55 \pm 22.526 \mathrm{~ms}, \mathrm{p}=0.856) \mathrm{Tp}$-e/ $\mathrm{QT}_{\max }(0.190 \pm 0.034$ vs. $0.203 \pm 0.031, \mathrm{p}=0.063), \quad \mathrm{Tp}-\mathrm{e} / \mathrm{JT}$ $(0.255 \pm 0.047$ vs. $0.267 \pm 0.036, \mathrm{p}=0.295)$ between the small heart group and control group (Table 2). For the JT, QT, and Tp-e measurements, the intra-observer difference between cardiologists was $2.5 \%, 3.4 \%$, and $4.3 \%$, respectively. Both the small heart group and control group shared a similar systematic error between the cardiologists.

\section{Discussion}

In this research, it has been found that there is a significant association between elevated cQTd, Tp-e interval, Tp-e/ $\mathrm{QTc}_{\max }$, and Tp-e/JTc ratios on surface ECG and small heart patients, in which they were considered to be correlated with ventricular arrhythmias and sudden death. We found that our literature review revealed no current study on the relationship between small heart syndrome and ventricular arrhythmia.

A variety of cardiac problems associated with low output syndrome are caused by small heart syndrome. In the assessment of those patients, diagnostic methods are particularly relevant, specifically chest radiography and ECG. The outcome of myocardial damage is low output

Table 1. Demographic and laboratory characteristics

\begin{tabular}{llll} 
& $\begin{array}{l}\text { Control } \\
\text { group } \\
(\mathbf{n}=47)\end{array}$ & $\begin{array}{l}\text { Small heart } \\
\text { group } \\
(\mathbf{n}=47)\end{array}$ & $\mathbf{p}$ \\
\hline Cardio-thoracic ratio & $46.413+3.007$ & $38.530+2.642$ & $<0.001^{*}$ \\
Age; years & $24.74+4.989$ & $22.87+5.029$ & 0.073 \\
Height; $\mathrm{cm}$ & $1.600+0.058$ & $1.622+0.063$ & 0.086 \\
Weight; $\mathrm{kg}$ & $59.51+13.592$ & $54.15+8.041$ & 0.061 \\
Body mass index; $\mathrm{kg} / \mathrm{cm}^{2}$ & $23.122+4.448$ & $20.597+3.031$ & $0.002^{*}$ \\
Systolic tension; $\mathrm{mmHg}$ & $98.53+5.120$ & $98.36+4.775$ & 0.868 \\
Diastolic tension; $\mathrm{mmHg}$ & $65.57+3.781$ & $67.43+4.596$ & 0.052 \\
Alanine & $16.94+14.039$ & $15.43+6.746$ & 0.847 \\
aminotransferase; IU/mL & & & \\
Aspartate & $18.60+7.039$ & $18.98+4.528$ & 0.146 \\
aminotransferase; IU/mL & & & \\
Creatinine; $\mathrm{mg} / \mathrm{dL}$ & $0.726+0.143$ & $0.757+0.219$ & 0.950 \\
Urea, mg/dL & $22.515+5.568$ & $22.134+5.627$ & 0.309 \\
Platelet; 103/ $\mu \mathrm{L}$ & $261.04+74.246$ & $255.30+59.553$ & 0.563 \\
Hemoglobin; $\mathrm{mg} / \mathrm{dL}$ & $13.670+1.233$ & $13.832+1.064$ & 0.498 \\
\hline
\end{tabular}


and it can end up causing ventricular arrhythmias. In patients with low output, malignant arrhythmias have been confirmed to be present (12).

The repolarization process offers valuable knowledge as a marker of arrhythmia in cardiac electrophysiology within the context of the probability of developing arrhythmia. QT range is significant in this regard in the 12-lead ECG. The QT interval is predominantly defined by the repolarization duration that refers to the JT interval. Thus, as a more acceptable indicator of ventricular repolarization than the QT, the JT interval has been suggested (13). In addition, through the analysis of the JT instead of the QT interval, the probability of incident cardiovascular episodes was better estimated $(14,15)$. In addition to the value of QT and JT intervals, useful parameters in terms of sensitivity to ventricular arrhythmias are Tp-e measurements, which are the predictors of ventricular arrhythmias, and their interaction with QT and JT distances (16-18). Cardiac screening should be carried out in younger patients with palpitations, chest pressure, and difficulty of breathing, by considering chest radiographs (19). Based on disorders like anxiety and panic attacks, the symptoms of these patients are normally dismissed by cardiologists. Furthermore, panic disorder patients demonstrated even greater ventricular repolarization parameters than healthy controls (20). Nevertheless, as our research indicates, these patients

Table 2. Electrocardiographic findings

\begin{tabular}{llll} 
& $\begin{array}{l}\text { Control group } \\
(\mathbf{n}=47)\end{array}$ & $\begin{array}{l}\text { Small heart } \\
\text { group } \\
(\mathbf{n}=\mathbf{4 7})\end{array}$ & $\mathbf{p}$ \\
Heart rate, bpm & $87.81+15.532$ & $83.81+14.372$ & 0.223 \\
QRS; ms & $83.23+6.948$ & $81.91+10.052$ & 0.206 \\
QT max; ms & $354.93+26.796$ & $358.54+28.434$ & 0.528 \\
QT min; ms & $330.68+26.611$ & $323.04+30.829$ & 0.202 \\
JT; ms & $265.7+25.16$ & $271.88+23.104$ & 0.218 \\
QTc max; ms & $403.59+18.208$ & $400.20+18.336$ & 0.371 \\
QTc min; ms & $379.34+20.064$ & $364.71+23.149$ & $0.004^{*}$ \\
JTc; ms & $314.37+21.325$ & $313.55+22.526$ & 0.856 \\
cQTd; ms & $24.246+9.046$ & $35.495+14.358$ & $<0.001^{*}$ \\
Tp-e; ms & $67.32+11.661$ & $72.67+11.028$ & $0.04^{*}$ \\
Tp-e/QT max & $0.190+0.034$ & $0.203+0.031$ & 0.063 \\
Tp-e/QTc max & $0.166+0.028$ & $0.181+0.027$ & $0.012^{*}$ \\
Tp-e/JT & $0.255+0.047$ & $0.267+0.036$ & 0.295 \\
Tp-e/JTc & $0.214+0.038$ & $0.232+0.034$ & $0.022^{*}$ \\
\hline
\end{tabular}

bpm: Beat per minute, ms: millisecond, QTc $c_{\text {max }}$ Corrected $\mathrm{QT}_{\text {max }^{\prime}} \mathrm{QTc}_{\min }$ : Corrected $\mathrm{QT}_{\text {min }}$ JT interval (JT): Were measured from the end of the QRS complex (J point) to the end of the T wave (JTend interval), JTc: Corrected JT interval, cQTd: cQT dispersion (QTd) was determined as the difference between the maximum and minimum QTc interval, Tp-e: T peak and end interval should bear in mind that, as they appear to have ventricular arrhythmias, supervision should be continued for more than 24 hours.

This idea is supported by the connection between this condition and chronic fatigue syndrome. Previous studies have identified the association between chronic fatigue syndrome and low output syndrome $(21,22)$. A widespread and complex chronic pain disorder, impacting $1 \%$ to $5 \%$ of the population, Fibromyalgia (FM) is defined as a chronic systemic pain that lasts for more than 3 months without any apparent organic lesion (23-25). Furthermore, it is known that chronic fatigue syndrome is connected with fibromyalgia, which is one of the leading symptoms of abnormal chest pain. The susceptibility of this group of patients with anxiety and depression to ventricular arrhythmias is also established $(26,27)$.

\section{Study Limitations}

A significant drawback is to make manual calculations rather than computer-based calculations for the quantities. For calculating QT values, automated measurement programs have been designed. Nevertheless, there have been still some challenges present with these systems (28). Based on several parameters, especially coronary artery disease and hormones, ventricular repolarization may differ (29). Since we did not get coronary angiography, we did not have adequate evidence to explain this concern. Analyses were conducted on the ECGs of the patients and echocardiography did not support these results.

\section{Conclusion}

As in the result of this retrospective study, it should be noted that when any arrhythmias are detected, patients having small hearth syndrome with improved prediction levels of ventricular arrhythmia should be monitored more closely through sequential ECG shots and reconfiguration. With this monitoring, the possibility of hemodynamic dysfunction that can lead to arrhythmia or cardiac arrest that can contribute to death can be reduced. To validate our findings, long term monitoring and extensive prospective investigations are necessary.

\section{Ethics}

Ethics Committee Approval: The study complies with the Declaration of Helsinki. University of Health Sciences Turkey, Gazi Yaşargil Training and Research Hospital approved the study protocol at 15/01/2021 with number of 625. 
Informed Consent: Informed consent was obtained from participants participating in the study in this article.

Peer-review: Externally peer-reviewed.

\section{Authorship Contributions}

Concept: E.İ., Design: E.İ., Data Collection or Processing: B.B., Analysis or Interpretation: B.B., Drafting Manuscript: E.İ., Critical Revision of Manuscript: B.B., Final Approval and Accountability: E.İ.

Conflict of Interest: No conflict of interest was declared by the authors.

Financial Disclosure: The authors declared that this study received no financial support.

\section{References}

1. Master AM. Neurocirculatory asthenia due to small heart. Med Clin North Am 1944;28(3):577-588.

2. Miwa K, Fujita M. Is small heart syndrome a "heart" disease or low output syndrome? Int J Cardiol 2011;146(1):95-96.

3. Pelter MM, Suba S, Sandoval C, Zègre-Hemsey JK, Berger S, Larsen A, et al. Actionable Ventricular Tachycardia During In-hospital ECG Monitoring and its Impact on Alarm Fatigue. Crit Pathw Cardiol 2020;19(2):79-86.

4. Suba S, Sandoval CP, Zègre-Hemsey JK, Hu X, Pelter MM. Contribution of Electrocardiographic Accelerated Ventricular Rhythm Alarms to Alarm Fatigue. Am J Crit Care 2019;28(3):222-229.

5. Tse G, Yan BP. Traditional and novel electrocardiographic conduction and repolarization markers of sudden cardiac death. Europace 2017;19(5):712-721.

6. Inanir M, Sincer I, Erdal E, Gunes Y, Cosgun M, Mansiroglu AK. Evaluation of electrocardiographic ventricular repolarization parameters in extreme obesity. J Electrocardiol 2018;53:36-39.

7. Miwa K, Fujita M. Small heart syndrome in patients with chronic fatigue syndrome. Clin Cardiol 2008;31(7):328-333.

8. Fukuda K, Straus SE, Hickle I, Sharpe Mc, Dobbins JG, Komaroff A. The chronic fatigue syndrome: a comprehensive approach to its definition and study. Ann Intern Med 1994;121(12):953-959.

9. Abe T. Small heart syndrome. Asian Med J 1990;33:295-302.

10. Hodges M, Salerno D, Erlien D. Bazett's QT correction reviewed. Evidence that a linear QT correction for heart is better. J Am Coll Cardiol 1983;1:694.

11. Hnatkova K, Johannesen L, Vicente J, Malik M. Heart rate dependency of JT interval sections. J Electrocardiol 2017;50(6):814824.

12. Cantillon DJ, Saliba WI, Wazni OM, Kanj M, Starling RC, Tang WHW, et al. Low Cardiac Output Associated With Ventricular Tachyarrhythmias in Continuous-Flow LVAD Recipients With a Concomitant ICD (LoCo VT Study) J Heart Lung Transplant 2014;33(3):318-320.

13. Spodick DH. Reduction of QT-interval imprecision and variance by measuring th eJT interval. Am J Cardiol 1992;70(1):628-629.
14. Tsai SF, Houmsse M, Dakhil B, Augostini R, Hummel JD, Kalbşeisch SJ, et al. QTc compared to JTc for monitoring drug-induced repolarization changes in the setting of ventricular pacing. Heart Rhythm 2014;11(3):485-491.

15. Zulqarnain MA, Qureshi WT, O'Neal WT, Shah AJ, Soliman EZ. Risk of mortality associated with QT and JT interval sat different levels of QRS duration (from the third national health and nutrition examination survey). Am J Cardiol 2015;116(1):74-78.

16. Monitillo F, Leone M, Rizzo C, Passantino A, Iacoviello M. Ventricular repolarization measures for arrhythmic risk stratification. World J Cardiol 2016;8(1):57-73.

17. Miwa K, Fujita M. Small heart with low cardiac output for orthostatic intolerance in patients with chronic fatigue syndrome. Clin Cardiol 2011;34(12):782-786.

18. Miwa K, Fujita M. Cardiovascular dysfunction with low cardiac output due to a small heart in patients with chronic fatigue syndrome. Intern Med 2009;48(21):1849-1854.

19. Katz C, Martin RD, Landa B, Chadda KD. Relationship of psychologic factors to frequent symptomatic ventricular arrhythmia. Am J Med 1985;78(4):589-594.

20. Jones GT, Atzeni F, Beasley M, FluB E, Sarzi-Puttini P, Macfarlane GJ. The prevalence of fibromyalgia in the general population: a comparison of the American College of Rheumatology 1990, 2010, and modified 2010 classification criteria. Arthritis Rheumatol 2015;67(2):568-575.

21. Choi DH and, Kim HS. Quantitative analysis of nailfold capillary morphology in patients with fibromyalgia. Korean J Intern Med 2015;30(4):531-537.

22. Son CN, Kim SH, Chang HW, Kim JM. A neurometabolite study of chronic daily headache in patients with systemic lupus erythematosus using magnetic resonance spectroscopy: comparison with fibromyalgia patients and healthy controls. Korean J Intern Med 2016;31(6):1171-1177.

23. Siepmann M, Kirch W. [Psychosomatic aspects of cardiac arrhythmias]. Med Klin (Munich) 2010;105(7):479-484.

24. Chugh SS, Reinier K, Singh T, Uy-Evanado A, Socoteanu C, Peters D, et al. Determinants of prolonged QT interval and their contribution to sudden death risk in coronary artery disease. Circulation 2009;119(5):663-670.

25. Panikkath R, Reinier K, Uy-Evanado A, Teodorescu C, Hattenhauer J, Mariani R, et al. Prolonged Tpeak to tend interval on the resting electrocardiogram is associated with increased risk of sudden cardiac death. Circ Arrhythm Electrophysiol 2011;4(4):441-447.

26. Miwa K, Fujita M. Cardiac Function fluctuates during exacerbation and remission in young adults with chronic fatigue syndrome and "small heart". J Cardiol 2009;54(1):29-35.

27. Afsin A, Asoğlu R, Orum MH, Cicekci E. Evaluation of TP-E Interval and TP-E/QT Ratio in Panic Disorder. Medicina (Kaunas) 2020;56(5):215.

28. Grasser EK, Ernst B, Thurnheer M, Schultes B. QT interval shortening after bariatric surgery depends on the applied heart rate correction equation. Obes Surg 2017;27(4):973-982.

29. James AF, Choisy SC, Hancox JC. Recent advances in understanding sex differences in cardiac repolarization. Prog Biophys Mol Biol 2007;94(3):265-319. 